\title{
Hyperglycaemia is associated with changes in the regional concentrations of glucose and myo-inositol within the brain
}

\author{
O. Heikkilä • N. Lundbom • M. Timonen • P.-H. Groop • \\ S. Heikkinen • S. Mäkimattila
}

Received: 21 August 2008 / Accepted: 30 November 2008/Published online: 19 December 2008

(C) Springer-Verlag 2008

\begin{abstract}
Aims/hypothesis The aim of the study was to assess the effect of hyperglycaemia on regional concentrations of glucose and other substrates within the brain in nondiabetic individuals and in patients with type 1 diabetes. Methods The brain metabolites of 17 men with type 1 diabetes and 12 age-matched non-diabetic men (22-43 years old) were studied after an overnight fast (plasma glucose $9.2 \pm 3.0$ vs $4.8 \pm 0.5 \mathrm{mmol} / 1$, respectively). $N$-Acetylaspartate (NAA), creatine, choline, myo-inositol (mI) and glucose in the frontal cortex, frontal white matter and thalamus were quantified with proton magnetic resonance spectroscopy.

Results In the non-diabetic participants, the glucose level was $47 \%$ higher $(p<0.01)$ in the frontal cortex than in the frontal white matter. In contrast, this regional variation was not observed in the diabetic participants, in whom the glucose level in the frontal white matter was $64 \%$ higher
\end{abstract}

The results of this study were presented in abstract form at the 17th Annual Meeting of the Diabetic Neuropathy Study Group (NEURODIAB) of the EASD in Utrecht, the Netherlands, 14-16 September 2007.

O. Heikkilä $(\bowtie) \cdot$ P.-H. Groop $\cdot$ S. Mäkimattila

Folkhälsan Research Center, Folkhälsan Institute of Genetics,

Biomedicum Helsinki (C330b), University of Helsinki,

P.O. Box 63, 00014 Helsinki, Finland

e-mail: outi.heikkila@helsinki.fi

O. Heikkilä • P.-H. Groop

Division of Nephrology, Department of Medicine,

Helsinki University Central Hospital,

Helsinki, Finland

N. Lundbom $\cdot$ M. Timonen

Helsinki Medical Imaging Center, University of Helsinki,

Helsinki, Finland

S. Heikkinen

Laboratory of Organic Chemistry, University of Helsinki,

Helsinki, Finland $(p<0.001)$ and in the frontal cortex $25 \%$ higher $(p=0.033)$ than that of the non-diabetic participants. In the diabetic participants, the glucose level in each of the three regions studied correlated with fasting plasma glucose $(r=0.88$ $0.67, p<0.01)$. In addition, in the diabetic participants, $\mathrm{mI}$ was $20 \%$ higher $(p<0.001)$ and NAA $6 \%$ lower $(p=0.037)$ in the frontal white matter, and $\mathrm{mI}$ was $8 \%$ higher $(p=$ 0.042 ) in the frontal cortex, than in the non-diabetic participants.

Conclusions/interpretation In type 1 diabetes, hyperglycaemia is associated with accumulation of glucose and $\mathrm{mI}$ in the cortex and in the white matter.

Keywords Brain metabolism - Glucose $\cdot$ Magnetic resonance spectroscopy $\cdot M y o$-inositol $\cdot N$-Acetylaspartate . Type 1 diabetes

$\begin{array}{ll}\text { Abbreviations } \\ \text { Cho } & \text { choline } \\ { }^{1} \mathrm{H}-\mathrm{MRS} & \text { proton magnetic resonance spectroscopy } \\ \mathrm{H}_{2} \mathrm{O} & \text { brain tissue water } \\ \mathrm{mI} & \text { myo-inositol } \\ \mathrm{NAA} & N \text {-acetylaspartate } \\ \mathrm{tCr} & \text { total creatine }\end{array}$

\section{Introduction}

Diabetes is a metabolic disorder that also involves the brain $[1,2]$. Some individuals with type 1 diabetes develop mild cognitive impairment in executive functions, most notably as reduced mental speed and diminished mental flexibility [3]. Type 1 diabetes is also associated with circulatory alterations that can lead to regional hypo- and hyperperfusion of the brain $[4,5]$ and to increased risk of lacunar infarcts and stroke $[6,7]$. In addition, structural changes, such as white matter hyperintensities [2] and cortical and 
subcortical atrophy $[8,9]$, have been reported to be more frequent in individuals with diabetes. Microangiopathy and impaired brain glucose metabolism have been suggested as possible explanations for these abnormalities [1, 10]. Recurrent hypoglycaemia has generally been considered to be the reason for the functional detriment of the brain, but recent evidence has suggested possible effects of acute [11] and chronic [10] hyperglycaemia. Therefore, a better understanding of the effects and consequences of hyperglycaemia on the brain is needed in order to develop strategies for preventing diabetes-related brain disease.

Proton magnetic resonance spectroscopy $\left({ }^{1} \mathrm{H}-\mathrm{MRS}\right)$ is a non-invasive method that can reveal metabolic changes in vivo even before functional or structural changes appear [12]. In individuals with diabetes, a decreased $N$-acetylaspartate (NAA):total creatine ( $\mathrm{tCr}$ ) ratio has been found in the white matter, pons and the basal ganglia, and this has been interpreted as representing dysfunction or loss of neurons [13-15]. In addition, increased myo-inositol (mI) level and $\mathrm{mI}: \mathrm{tCr}$ ratios have been observed both in the cortical grey matter and in the white matter, suggesting altered cellular signal transduction [16], osmosis [16, 17] or gliosis [18]. Finally, increased choline (Cho) in the white matter, pons and thalamus, as well as changes in the Cho: $\mathrm{tCr}$ ratio in the cortex, have been interpreted as an indication of increased cell membrane turnover or gliosis $[13,16,18]$. However, most of these previous studies have included a mixture of patients with type 1 and type 2 diabetes, as well as patients with ketoacidosis.

The brain glucose concentration has been reported to be 2-3 mmol/l higher in diabetic than in non-diabetic individuals, not only in the parietal and occipital cortices, but also in the frontal white matter and thalamus $[15,16$, 19]. Glucose concentrations have been found to be higher in the parietal than in the occipital cortex in individuals with diabetes, suggesting regional differences [15]. Thus, some parts of the brain are presumably exposed to glucose to a greater degree than others, and it is possible that tolerance to hyperglycaemia may vary regionally due to circulatory and compositional factors. The aim of this study was therefore to assess the effect of hyperglycaemia on the regional concentration of glucose and other substrates within the brains of non-diabetic individuals and patients with type 1 diabetes.

\section{Methods}

Participants Seventeen individuals with type 1 diabetes and 12 non-diabetic control individuals volunteered for the study. The participants with diabetes were recruited from the outpatient clinic of the Helsinki University Central Hospital and the non-diabetic participants by advertise- ments in the Helsinki metropolitan area. They were nonsmoking men, 22-43 years old, without a family history of type 2 diabetes, and with no signs or symptoms of cerebrovascular, cardiovascular, neurological or psychiatric disease, and with no history of head trauma. The diabetic participants had no history of unconsciousness due to hypoglycaemia. Previous or present alcohol abuse or drug abuse were exclusion criteria. The participants had no regular medication, except for insulin in the diabetic patients.

The participants had no clinical symptoms or signs of peripheral neuropathy. Fifteen diabetic participants had a normal urinary albumin excretion rate $(<30 \mathrm{mg} / 24 \mathrm{~h})$; one excreted $32 \mathrm{mg} / 24 \mathrm{~h}$ and another $38 \mathrm{mg} / 24 \mathrm{~h}$. Retinopathy was quantified from fundus photographs by an ophthalmologist using the Early Treatment Diabetic Retinopathy Study (ETDRS) scale [20] in a blinded fashion. Three of the diabetic participants had background diabetic retinopathy, whereas the others had no signs of retinopathy.

The ethics committee of the Helsinki University Central Hospital approved the study and informed written consent was obtained from all participants.

Study design The diabetic participants were instructed to measure their blood glucose level at least seven times during the day before the study visit. Hypoglycaemic symptoms or measured hypoglycaemia $(<2.9 \mathrm{mmol} / \mathrm{l})$ in the preceding $24 \mathrm{~h}$ led to re-scheduling of the study visit. In the morning of the study, the diabetic patients using NPH insulin $(n=5)$ reduced their normal dose by $50 \%$ to avoid hypoglycaemia during fasting, whereas the patients using glargine insulin $(n=12)$ injected their normal dose.

All participants were studied after a $12 \mathrm{~h}$ fast. Blood pressure was measured in the sitting position after a 10 min rest. A cannula was placed in the right antecubital vein for collection of basal blood samples and for sodium chloride infusion. A retrograde cannula was placed in the left dorsal hand vein to obtain arterialised fasting plasma glucose and serum insulin samples before and after the brain imaging [21].

Magnetic resonance imaging and spectroscopy A $1.5 \mathrm{~T}$ magnetic resonance imager (Siemens Magnetom Sonata, Erlangen, Germany) was used with a standard quadrature birdcage head coil for measuring changes in tissue substrate levels. T1-weighted sagittal, T2-weighted coronal and fast fluid-attenuated inversion-recovery (FLAIR) axial images were collected for morphological assessment and positioning of the proton magnetic resonance spectroscopy $\left({ }^{1} \mathrm{H}-\right.$ MRS) voxels. Magnetic resonance images were evaluated by a neuroradiologist blinded to the clinical data.

Localised ${ }^{1} \mathrm{H}$-MRS was performed using the point-resolved spectroscopy sequence (PRESS), chemical shift-selective (CHESS) water suppression scheme, echo time of $30 \mathrm{~ms}$, repetition time of $3,000 \mathrm{~ms}$, and 64 repetitions. Water- 
suppressed metabolite spectra were collected in the frontal cortex $\left(25 \times 16 \times 20 \mathrm{~mm}^{3}=8.0 \mathrm{ml}\right)$, frontal white matter $(30 \times$ $\left.16 \times 16 \mathrm{~mm}^{3}=7.7 \mathrm{ml}\right)$ and left thalamus region $(20 \times 20 \times$ $20 \mathrm{~mm}^{3}=8.0 \mathrm{ml}$ ). Non-water-suppressed spectra were collected using four acquisitions in the same volumes. The spectral width of $1,000 \mathrm{~Hz}$ was covered by acquiring 1,024 complex data points. The data collection time was $30 \mathrm{~min}$.

The spectra were analysed with Matlab 7.2 (MathWorks, Natick, MA, USA). The free induction decay (FID) was apodised with a Gaussian function with a broadening of $2.5 \mathrm{~Hz}$ and zero-filled up to 2,048 complex points prior to Fourier transformation. Signal intensities were evaluated by integration of the spectral regions and were automatically corrected for coil-loading and voxel size by the analysis program; receiver gain was kept constant. Of the 87 spectra collected, eight were excluded due to inadequate quality (four from the diabetic group and four from the nondiabetic group).

The quantified resonances included NAA, Cho, tCr, mI, glucose and tissue water $\left(\mathrm{H}_{2} \mathrm{O}\right)$, as shown in Fig. 1. The signal intensities were evaluated by integration of the spectral regions: NAA 1.98-2.06, Cho 3.18-3.27, tCr 3.00-3.08, mI 3.52-3.60, glucose 3.40-3.46 and $\mathrm{H}_{2} \mathrm{O} 4.2-5.2 \mathrm{ppm}$. They were analysed as metabolite: $\mathrm{H}_{2} \mathrm{O}$ ratios to minimise the effect of random fluctuations in the intensity levels originated from the instrument or the participant [22].

Laboratory analysis Plasma glucose was analysed with the glucose oxidase method (Beckman Glucose Analyzer II; Beckman Instruments, Fullerton, CA, USA) and fasting serum insulin with the time-resolved fluoroimmunoassay

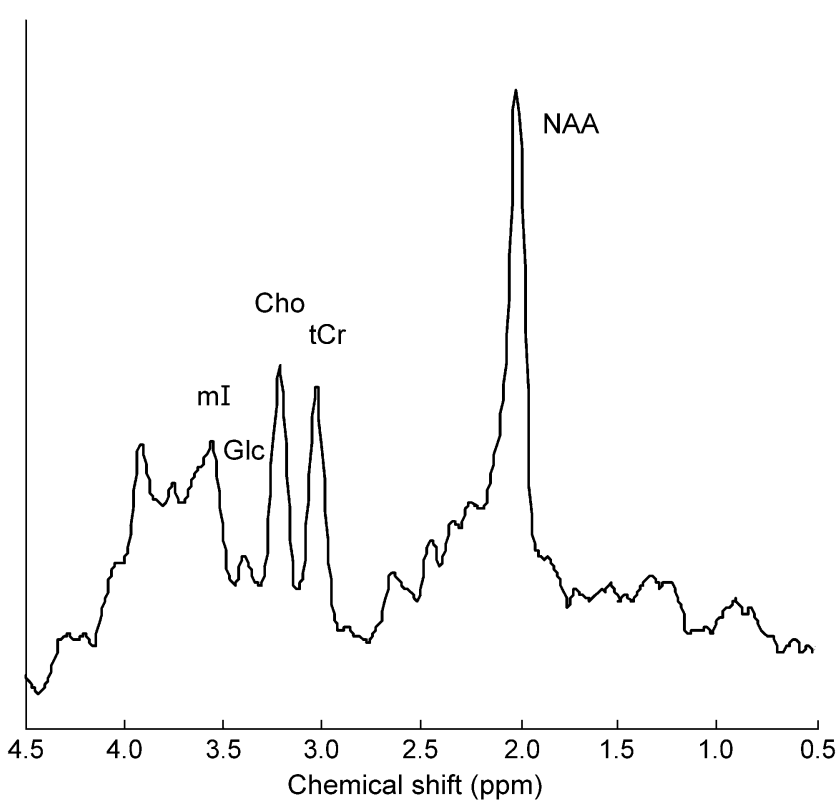

Fig. 1 A typical frontal white matter spectrum of a participant with type 1 diabetes. Glc, glucose
(PerkinElmer, Turku, Finland). $\mathrm{HbA}_{1 \mathrm{c}}$ was analysed by an immunoturbidimetric assay (Bayer, Tarrytown, NY, USA). Serum concentrations of triacylglycerol, total cholesterol and HDL-cholesterol were determined using enzymatic photometric assays (Roche Diagnostics, Mannheim, Germany), and LDL-cholesterol was calculated using Friedewald's formula [23]. Plasma C-reactive protein was analysed immunoturbimetrically (Orion Diagnostica, Espoo, Finland), endothelial selectin using commercial immunoassays (R\&D System, Minneapolis, MN, USA) and plasma homocysteine with an enzymatic assay (Axis-Shield Diagnostics, Dundee, UK). Urinary albumin excretion rate was determined in $24 \mathrm{~h}$ urine collections with immunoturbidimetry (Orion Diagnostica).

Statistical methods The statistical significance of differences in variables between groups and between studied brain regions was analysed using Student's $t$ test for continuous variables. Correlations between the brain glucose levels and plasma glucose concentrations were assessed with the Pearson correlation coefficient. Due to the small sample size, the analyses were confirmed using non-parametric tests (two-tailed Mann-Whitney $U$ and Spearman pair-wise rank-order correlation tests), which gave similar results. Power calculations were performed based on our previous study with the ${ }^{1} \mathrm{H}-\mathrm{MRS}$ [16]. With a sample size of 17 individuals with diabetes and 12 without diabetes, the study had $80 \%$ power to detect a $20 \%$ difference $\left(9 \times 10^{-6} \mathrm{IU}\right)$ in the brain glucose: $\mathrm{H}_{2} \mathrm{O}$ ratios at a two-sided significance level of 5\% [24]. Data are given as means \pm SD and $p$ values $<0.05$ were considered statistically significant. The analyses were performed with the Sigma Stat Statistical Software SPSS 15.0 (SPSS, Chicago, IL, USA).

\section{Results}

Clinical and biochemical characteristics The clinical characteristics of the participants are presented in Table 1 . Plasma glucose and serum insulin concentrations remained stable during the $30 \mathrm{~min}{ }^{1} \mathrm{H}-\mathrm{MRS}$ data collection. The plasma glucose concentrations before and after the data collection were $9.7 \pm 3.3$ and $8.7 \pm 2.9 \mathrm{mmol} / 1(p=0.361)$ in the diabetic participants, and $4.7 \pm 0.4$ and $4.8 \pm 0.6 \mathrm{mmol} / 1$ $(p=0.628)$ in the non-diabetic participants, respectively. The serum insulin concentrations before and after the data collection were $29.6 \pm 39.9$ and $31.4 \pm 44.2 \mathrm{pmol} / 1$ $(p=0.905)$ in the diabetic participants and $22.8 \pm 6.7$ and $17.7 \pm 6.6 \mathrm{pmol} / \mathrm{l}(p=0.083)$ in the non-diabetic participants, respectively. The mean of glucose and insulin concentrations before and after data collection were used in the analyses (Table 1). 
Table 1 Characteristics of the participants

\begin{tabular}{|c|c|c|c|}
\hline Characteristic & Type 1 diabetes $(n=17)$ & Non-diabetic $(n=12)$ & $p$ value \\
\hline Age (years) & $28.2 \pm 4.4(22-34)$ & $29.5 \pm 6.0(23-43)$ & 0.526 \\
\hline Age at onset of diabetes (years) & $21 \pm 6(21-33)$ & - & \\
\hline Diabetes duration (years) & $7 \pm 5(1-16)$ & - & \\
\hline Waist circumference $(\mathrm{cm})$ & $88 \pm 8(73-102)$ & $83 \pm 5(74-94)$ & 0.088 \\
\hline Body mass index $\left(\mathrm{kg} / \mathrm{m}^{2}\right)$ & $24.7 \pm 3.0(17.6-30.6)$ & $22.4 \pm 2.1(18.4-26.4)$ & 0.019 \\
\hline Systolic blood pressure $(\mathrm{mmHg})$ & $133 \pm 7(123-152)$ & $125 \pm 7(110-136)$ & 0.009 \\
\hline Diastolic blood pressure $(\mathrm{mmHg})$ & $75 \pm 7(64-91)$ & $73 \pm 8(56-83)$ & 0.483 \\
\hline Heart rate (beats/min) & $64 \pm 9(53-73)$ & $60 \pm 10(39-72)$ & 0.122 \\
\hline Serum total cholesterol $(\mathrm{mmol} / \mathrm{l})$ & $4.3 \pm 0.9(3.1-6.0)$ & $4.2 \pm 0.9(3.1-6.0)$ & 0.682 \\
\hline Serum LDL-cholesterol $(\mathrm{mmol} / \mathrm{l})$ & $2.3 \pm 0.9(1.2-4.0)$ & $2.4 \pm 0.9(1.1-4.2)$ & 0.710 \\
\hline Serum HDL-cholesterol $(\mathrm{mmol} / \mathrm{l})$ & $1.6 \pm 0.3(1.0-2.1)$ & $1.5 \pm 0.3(1.0-2.0)$ & 0.300 \\
\hline Serum triacylglycerol $(\mathrm{mmol} / \mathrm{l})$ & $0.9 \pm 0.4(0.4-2.0)$ & $0.7 \pm 0.3(0.4-1.3)$ & 0.217 \\
\hline $\mathrm{HbA}_{1 \mathrm{c}}(\%)^{\mathrm{a}}$ & $7.4 \pm 1.1(5.4-10.2)$ & $5.5 \pm 0.2(5.3-5.8)$ & 0.001 \\
\hline Plasma glucose $(\mathrm{mmol} / \mathrm{l})$ & $9.2 \pm 3.0(4.7-15.1)$ & $4.8 \pm 0.5(4.2-6.0)$ & 0.001 \\
\hline Serum insulin (pmol/1) & $30.5 \pm 42.0(2.9-136.8)$ & $20.8 \pm 6.5(8.7-33.0)$ & 0.437 \\
\hline Albumin excretion rate $(\mathrm{mg} / 24 \mathrm{~h})$ & $12 \pm 10(2-38)$ & $11 \pm 8(2-32)$ & 0.747 \\
\hline Plasma C-reactive protein (mg/l) & $0.5 \pm 0.9(0.1-3.7)$ & $0.4 \pm 0.4(0.1-1.1)$ & 0.604 \\
\hline Plasma homocysteine $(\mu \mathrm{mol} / \mathrm{l})$ & $6.5 \pm 2.4(2.2-12.2)$ & $8.0 \pm 1.8(5.5-11.4)$ & 0.074 \\
\hline Serum soluble endothelial selectin $(\mathrm{ng} / \mathrm{ml})$ & $41.3 \pm 17.9(13.0-85.8)$ & $30.6 \pm 14.6(9.7-56.4)$ & 0.095 \\
\hline Social class: white/blue collar workers $(n)$ & $12 / 5$ & $9 / 3$ & \\
\hline
\end{tabular}

Data are means $\pm \mathrm{SD}$ (range)

${ }^{a}$ Reference range $4-6 \%$

Proton magnetic resonance imaging and spectroscopy All participants had brain magnetic resonance images in the normal range. Tissue $\mathrm{H}_{2} \mathrm{O}$ levels were similar in the diabetic and non-diabetic participants: frontal cortex $299 \times$ $10^{6} \pm 13 \times 10^{6}$ vs $298 \times 10^{6} \pm 10 \times 10^{6}$ IU $(p=0.809)$; frontal white matter $279 \times 10^{6} \pm 9 \times 10^{6}$ vs $274 \times 10^{6} \pm 9 \times 10^{6} \mathrm{IU}(p=$ $0.152)$; and thalamus $270 \times 10^{6} \pm 13 \times 10^{6}$ vs $264 \times 10^{6} \pm 8 \times$ $10^{6} \mathrm{IU}(p=0.175)$, respectively.

Brain glucose Brain glucose: $\mathrm{H}_{2} \mathrm{O}$ ratios are shown in Table 2 and Fig. 2. In the non-diabetic participants, the brain glucose level was $47 \%(p<0.01)$ higher in the frontal cortex than in the frontal white matter. In the diabetic participants, there were no regional differences in the brain glucose levels.

Compared with the non-diabetic participants, the diabetic participants had a $64 \%(p<0.001)$ higher glucose level in the frontal white matter and a $25 \%(p=0.033)$ higher glucose level in the frontal cortex (Table 2). There was no between-group difference in the glucose level in the thalamus (Table 2).

The plasma glucose concentration was correlated significantly with the brain glucose level in the frontal cortex $(r=0.88, p<0.0001$; Fig. 2a), frontal white matter $(r=0.78$, $p<0.001$; Fig. $2 \mathrm{~b})$ and thalamus $(r=0.67, p<0.01)$ in the diabetic participants, but not in the non-diabetic participants.
Brain metabolites Brain metabolite: $\mathrm{H}_{2} \mathrm{O}$ ratios are shown in Table 2. The diabetic participants had $20 \%$ higher $\mathrm{mI}$ $(p<0.001)$ and $6 \%$ lower NAA $(p=0.037)$ in the frontal white matter, and $8 \%$ higher $\mathrm{mI}$ in the frontal cortex $(p=$ 0.042), than the non-diabetic participants.

Table 2 Ratios of brain metabolite: $\left(\mathrm{H}_{2} \mathrm{O} \times 10^{-6}\right)$

\begin{tabular}{lccr}
\hline Metabolite & Type 1 diabetes & Non-diabetic & $p$ value \\
\hline Frontal cortex & & & \\
Glucose & $46.8 \pm 12.4$ & $37.3 \pm 9.6$ & 0.033 \\
NAA & $395.4 \pm 24.8$ & $409.7 \pm 26.9$ & 0.163 \\
tCr & $231.9 \pm 23.2$ & $237.6 \pm 26.0$ & 0.553 \\
Cho & $185.7 \pm 27.2$ & $173.6 \pm 11.6$ & 0.161 \\
mI & $194.8 \pm 13.3$ & $180.2 \pm 19.6$ & 0.042 \\
Frontal white matter & & \\
Glucose & $41.5 \pm 11.9$ & $25.3 \pm 6.3$ & $<0.001$ \\
NAA & $445.5 \pm 23.4$ & $470.3 \pm 32.7$ & 0.037 \\
tCr & $215.7 \pm 22.4$ & $216.5 \pm 14.8$ & 0.919 \\
Cho & $206.9 \pm 21.8$ & $193.8 \pm 13.0$ & 0.076 \\
mI & $182.5 \pm 17.8$ & $152.4 \pm 17.1$ & $<0.001$ \\
Thalamus & & & \\
Glucose & $41.5 \pm 12.2$ & $30.7 \pm 14.6$ & 0.072 \\
NAA & $420.0 \pm 25.2$ & $438.8 \pm 31.4$ & 0.120 \\
tCr & $235.2 \pm 15.1$ & $226.2 \pm 25.8$ & 0.275 \\
Cho & $197.3 \pm 21.0$ & $186.1 \pm 19.6$ & 0.178 \\
mI & $169.5 \pm 16.1$ & $150.5 \pm 32.2$ & 0.062 \\
\hline
\end{tabular}

Data are means $\pm \mathrm{SD}$ 

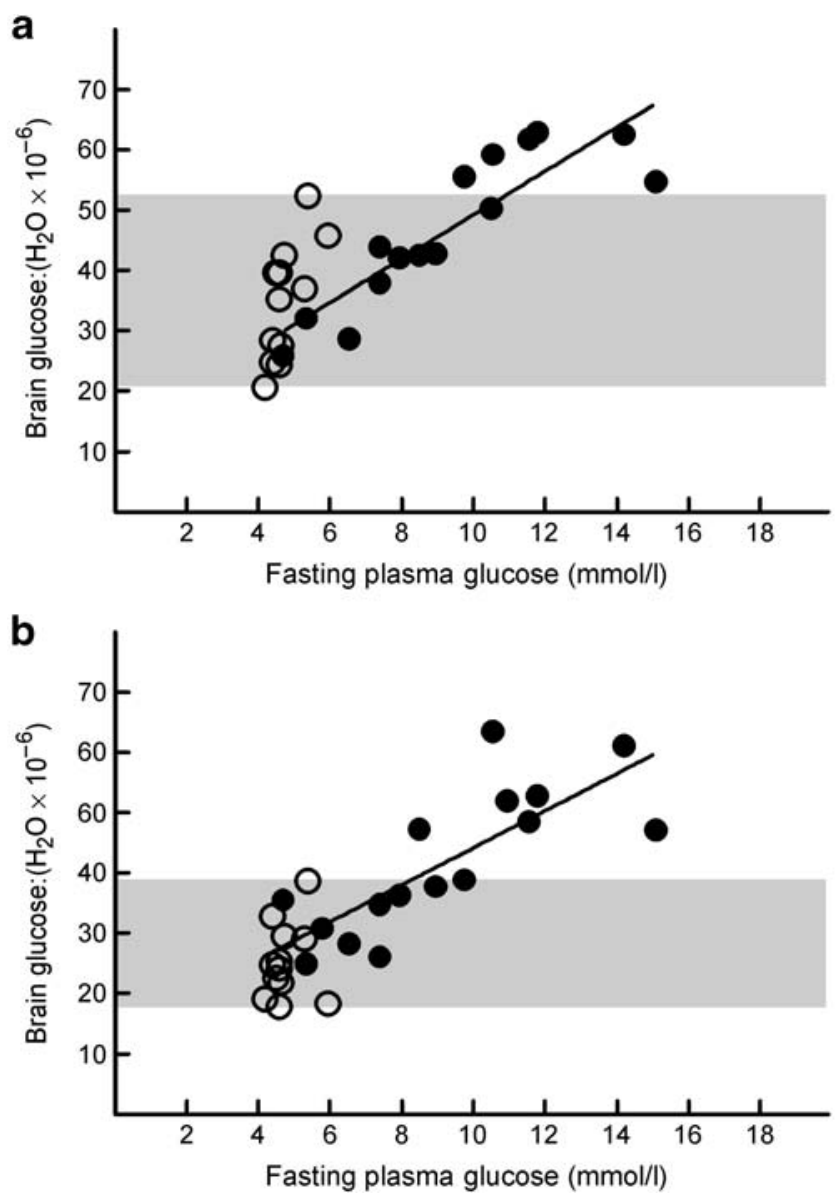

Fig. 2 Relationship between fasting plasma glucose and brain glucose level in the frontal cortex (a) and in the frontal white matter (b). White circles, non-diabetic participants; black circles, participants with type 1 diabetes. The grey areas represent the ranges for non-diabetic participants. For diabetic participants: $r=0.88, p<0.0001$ (a); $r=0.78$, $p<0.001$ (b)

\section{Discussion}

We report three main findings in participants with type 1 diabetic. First, brain glucose levels were higher in diabetic participants than in non-diabetic participants and levels were correlated with fasting plasma glucose concentrations. Second, there were no regional differences in the brain glucose levels in patients with diabetes, which is in contrast to the findings in non-diabetic participants. Third, both the accumulation of glucose and the brain metabolite alterations were most pronounced in the frontal white matter. These results were obtained using a novel approach: quantification of glucose levels simultaneously in several brain regions using ${ }^{1} \mathrm{H}$-MRS.

The aim of this study was to investigate the effect of hyperglycaemia on the concentrations of glucose and other substrates within the brain. We therefore chose to study a well characterised and homogenous group of patients. In order to achieve this goal we tried to exclude any effects of childhood diabetes on the developing brain $[25,26]$, as well as any age-related changes in the brain parenchyma, and studied specifically young adults with late-onset of type 1 diabetes. Furthermore, we included only men because brain metabolite concentrations change with the menstrual cycle in women [27]. It is of note that recurrent hypoglycaemic events [28], accumulation of several microvascular complications, and retinopathy or polyneuropathy alone [29-31] are associated with impaired brain function. Therefore, the individuals initially eligible for this study were excluded if they had any history of severe hypoglycaemia or clinical signs of severe micro- or macrovascular complications (Table 1). The impact of blood pressure, lipid profile, homocysteine, C-reactive protein, endothelial selectin and social class were assessed in order to control for factors that increase the risk of micro- and macrovascular endothelial injury $[32,33]$. Nevertheless, the small number of participants and the cross-sectional study design are important limitations of this study.

${ }^{1} \mathrm{H}-\mathrm{MRS}$ is the method of choice to assess regional distribution of glucose in the brain and to search for concurrent metabolic alterations. It enables the quantification of native brain glucose during fasting glycaemia without glucose infusion. It would of course be possible to estimate the absolute concentrations of glucose and metabolites, but this would require phantom measurements and correction factors, thus adding inaccuracy through assumptions. We therefore chose to use the metabolite: $\mathrm{H}_{2} \mathrm{O}$ ratio, which is the standard method reported in the literature on ${ }^{1} \mathrm{H}-\mathrm{MRS}$ [22].

Brain glucose concentrations have previously been found to vary linearly with plasma glucose concentration in a range of 4.4 to $24.5 \mathrm{mmol} / \mathrm{l}$ in non-diabetic individuals during a hyperglycaemic clamp [34]. We did not find this association in non-diabetic individuals during fasting. The discrepancy with previous clamp data may be due to the relatively small range of plasma and brain glucose concentrations in the non-diabetic participants. We were, however, able to show a relationship between brain and plasma glucose concentrations in the frontal cortex, the frontal white matter and the thalamus during fasting (plasma glucose range $4.7-15.1 \mathrm{mmol} / \mathrm{l}$ ) in diabetic individuals. This suggests that plasma glucose concentration is an important determinant of brain glucose content.

Regional differences in the brain glucose levels have previously been assessed only in the posterior parts of the brain in non-diabetic individuals, and these studies have not been able to show differences between the occipital cortex and centrum semiovale. We observed a $47 \%$ higher glucose level in the cortex than in the white matter of the frontal lobe. Compared with previous studies, our sample was more homogenous, and we studied younger individuals with a smaller age range and only men. A smaller voxel 
size also allowed higher tissue specificity. It is of note that the glucose level in the brain tissue is determined by its supply via blood flow, transport through the blood-brain barrier and its metabolic rate in the brain tissue. The grey matter has both a higher perfusion rate [4] and a higher oxidation rate of glucose $[35,36]$ than the white matter. Our finding suggests that the supply of glucose in relation to its oxidation is greater in the frontal cortex than in the white matter.

In the diabetic participants, with an average plasma glucose concentration of $9.2 \mathrm{mmol} / \mathrm{l}$, we found no regional differences in the brain glucose levels. This is in accordance with previous studies performed in non-diabetic individuals during a hyperglycaemic clamp [34, 37, 38]. These studies did not show any differences in glucose levels between either the centrum semiovale and frontal cortex with ${ }^{1} \mathrm{H}-{ }^{13} \mathrm{C}-\mathrm{MRS}$ [37], or the centrum semiovale and occipital cortex with ${ }^{1} \mathrm{H}$-MRS $[34,38]$. Our findings suggest that even relatively mild hyperglycaemia not only increases brain glucose levels, but also reduces the differences between brain regions.

The difference in glucose levels between the nondiabetic and diabetic participants was greatest in the frontal white matter, which suggests that compared with the cortical grey matter and the thalamus, the white matter may be inferior in its ability to protect itself from the excess glucose. In keeping with this idea, in diabetic participants changes in brain metabolites were most pronounced in the frontal white matter. The present study cannot identify the mechanisms that underlie the different behaviour of grey and white matter, but tissue composition may play a role.

The diabetic participants had $8 \%$ higher $\mathrm{mI}$ in the frontal cortex and $20 \%$ higher $\mathrm{mI}$ in the frontal white matter than the non-diabetic participants. This is in accordance with previous studies, which have reported increased $\mathrm{mI}$ levels in the frontal [17], parietal and occipital [15] cortices, and in the white matter [16] of diabetic individuals. Since $\mathrm{mI}$ is derived from glucose, one reason for the increased $\mathrm{mI}$ during hyperglycaemia may be the abundance of the precursor [38]. $\mathrm{mI}$ is also considered to be an intracellular second messenger and an osmoregulator [39], and studies in rats have provided evidence that its transport into hyperosmolar brain cells is upregulated [40].

We found a $6 \%$ decreased NAA in the frontal white matter in diabetic participants compared with non-diabetic participants. This observation replicates some $[13,15]$ but not all $[16,17]$ previous studies. NAA is a neuron-specific amino acid [41, 42] and decreased levels are related to neuronal dysfunction [43].

Taken together, our results suggest that in type 1 diabetes, the white matter of the brain is more readily exposed to glucose than the grey matter, and they support the theory [10] of a specific vulnerability of the white matter. Longstanding type 1 diabetes is associated with deficits detectable by neurocognitive tests that are suggestive of white matter dysfunction [3]. Such cognitive decline in diabetic individuals has recently also been associated with decreased volume of the white matter [44] and with deficits in the white matter microstructure [45]. Our results suggest that hyperglycaemia per se may have a detrimental effect on the brain in diabetes and its role should be studied further.

Acknowledgements Financial support was provided by grants from the Folkhälsan Research Foundation, the Finnish Medical Society (Finska Läkaresällskapet), the Diabetes Research Foundation, Waldemar von Frenckell's Foundation, and the Wilhelm and Else Stockmann Foundation, and from a special governmental grant for health sciences research (no. 5103). The assistance of ophthalmologist K. Hietala (for sharing his expertise in viewing fundus photographs), laboratory technicians T. Vesisenaho, A. Sandelin and S. Lindh, and radiology technician M. Piitulainen is gratefully acknowledged.

Duality of interest The authors declare that there is no duality of interest associated with this manuscript.

\section{References}

1. McCall AL (1992) The impact of diabetes on the CNS. Diabetes 41:557-570

2. van Harten B, de Leeuw FE, Weinstein HC, Scheltens P, Biessels GJ (2006) Brain imaging in patients with diabetes: a systematic review. Diabetes Care 29:2539-2548

3. Brands AM, Biessels GJ, de Haan EH, Kappelle LJ, Kessels RP (2005) The effects of type 1 diabetes on cognitive performance: a meta-analysis. Diabetes Care 28:726-735

4. Keymeulen B, Jacobs A, de Metz K, de Sadeleer C, Bossuyt A, Somers G (1995) Regional cerebral hypoperfusion in long-term type 1 (insulin-dependent) diabetic patients: relation to hypoglycaemic events. Nucl Med Commun 16:10-16

5. Quirce R, Carril JM, Jimenez-Bonilla JF et al (1997) Semiquantitative assessment of cerebral blood flow with ${ }^{99 \mathrm{~m}} \mathrm{Tc}$ HMPAO SPET in type I diabetic patients with no clinical history of cerebrovascular disease. Eur J Nucl Med 24:1507-1513

6. Laing SP, Swerdlow AJ, Carpenter LM et al (2003) Mortality from cerebrovascular disease in a cohort of 23000 patients with insulin-treated diabetes. Stroke 34:418-421

7. Nathan DM, Cleary PA, Backlund JY et al (2005) Intensive diabetes treatment and cardiovascular disease in patients with type 1 diabetes. N Engl J Med 353:2643-2653

8. Musen G, Lyoo IK, Sparks CR et al (2006) Effects of type 1 diabetes on gray matter density as measured by voxel-based morphometry. Diabetes 55:326-333

9. Wessels AM, Simsek S, Remijnse PL et al (2006) Voxel-based morphometry demonstrates reduced grey matter density on brain MRI in patients with diabetic retinopathy. Diabetologia 49:2474-2480

10. Wessels AM, Scheltens P, Barkhof F, Heine RJ (2008) Hyperglycaemia as a determinant of cognitive decline in patients with type 1 diabetes. Eur J Pharmacol 585:88-96

11. Cox DJ, Kovatchev BP, Gonder-Frederick LA et al (2005) Relationships between hyperglycemia and cognitive performance among adults with type 1 and type 2 diabetes. Diabetes Care 28:71-77

12. Vrenken H, Barkhof F, Uitdehaag BM, Castelijns JA, Polman CH, Pouwels PJ (2005) MR spectroscopic evidence for glial increase 
but not for neuro-axonal damage in MS normal-appearing white matter. Magn Reson Med 53:256-266

13. Sarac K, Akinci A, Alkan A, Aslan M, Baysal T, Ozcan C (2005) Brain metabolite changes on proton magnetic resonance spectroscopy in children with poorly controlled type 1 diabetes mellitus. Neuroradiology 47:562-565

14. Wootton-Gorges SL, Glaser NS (2007) Imaging of the brain in children with type I diabetes mellitus. Pediatr Radiol 37:863-869

15. Kreis R, Ross BD (1992) Cerebral metabolic disturbances in patients with subacute and chronic diabetes mellitus: detection with proton MR spectroscopy. Radiology 184:123-130

16. Mäkimattila S, Malmberg-Ceder K, Häkkinen AM et al (2004) Brain metabolic alterations in patients with type 1 diabeteshyperglycemia-induced injury. J Cereb Blood Flow Metab 24:1393-1399

17. Cameron FJ, Kean MJ, Wellard RM, Werther GA, Neil JJ, Inder TE (2005) Insights into the acute cerebral metabolic changes associated with childhood diabetes. Diabet Med 22:648-653

18. Geissler A, Frund R, Scholmerich J, Feuerbach S, Zietz B (2003) Alterations of cerebral metabolism in patients with diabetes mellitus studied by proton magnetic resonance spectroscopy. Exp Clin Endocrinol Diabetes 111:421-427

19. Criego AB, Tkac I, Kumar A, Thomas W, Gruetter R, Seaquist ER (2005) Brain glucose concentrations in patients with type 1 diabetes and hypoglycemia unawareness. J Neurosci Res 79:42-47

20. Davis MD, Fisher MR, Gangnon RE et al (1998) Risk factors for high-risk proliferative diabetic retinopathy and severe visual loss: Early Treatment Diabetic Retinopathy Study Report \#18. Invest Ophthalmol Vis Sci 39:233-252

21. McGuire EA, Helderman JH, Tobin JD, Andres R, Berman M (1976) Effects of arterial versus venous sampling on analysis of glucose kinetics in man. J Appl Physiol 41:565-573

22. Urrila AS, Hakkarainen A, Heikkinen S et al (2006) Preliminary findings of proton magnetic resonance spectroscopy in occipital cortex during sleep deprivation. Psychiatry Res 147:41-46

23. Friedewald WT, Levy RI, Fredrickson DS (1972) Estimation of the concentration of low-density lipoprotein cholesterol in plasma, without use of the preparative ultracentrifuge. Clin Chem 18:499-502

24. Campbell MJ, Julious SA, Altman DG (1995) Estimating sample sizes for binary, ordered categorical, and continuous outcomes in two group comparisons. BMJ 311:1145-1148

25. Ferguson SC, Blane A, Wardlaw J et al (2005) Influence of an early-onset age of type 1 diabetes on cerebral structure and cognitive function. Diabetes Care 28:1431-1437

26. Schoenle EJ, Schoenle D, Molinari L, Largo RH (2002) Impaired intellectual development in children with type I diabetes: association with $\mathrm{HbA}(1 \mathrm{c})$, age at diagnosis and sex. Diabetologia 45:108-114

27. Rasgon NL, Thomas MA, Guze BH et al (2001) Menstrual cyclerelated brain metabolite changes using $1 \mathrm{H}$ magnetic resonance spectroscopy in premenopausal women: a pilot study. Psychiatry Res 106:47-57

28. Lincoln NB, Faleiro RM, Kelly C, Kirk BA, Jeffcoate WJ (1996) Effect of long-term glycemic control on cognitive function. Diabetes Care 19:656-658
29. Ryan CM, Geckle MO, Orchard TJ (2003) Cognitive efficiency declines over time in adults with type 1 diabetes: effects of microand macrovascular complications. Diabetologia 46:940-948

30. Ferguson SC, Blane A, Perros P et al (2003) Cognitive ability and brain structure in type 1 diabetes: relation to microangiopathy and preceding severe hypoglycemia. Diabetes 52:149-156

31. Ryan CM, Williams TM, Finegold DN, Orchard TJ (1993) Cognitive dysfunction in adults with type 1 (insulin-dependent) diabetes mellitus of long duration: effects of recurrent hypoglycaemia and other chronic complications. Diabetologia 36:329-334

32. Bonora E (2006) The metabolic syndrome and cardiovascular disease. Ann Med 38:64-80

33. Li C, Hedblad B, Rosvall M, Buchwald F, Khan FA, Engstrom G (2008) Stroke incidence, recurrence, and case-fatality in relation to socioeconomic position: a population-based study of middle-aged Swedish men and women. Stroke 39:2191-2196

34. Seaquist ER, Damberg GS, Tkac I, Gruetter R (2001) The effect of insulin on in vivo cerebral glucose concentrations and rates of glucose transport/metabolism in humans. Diabetes 50: 2203-2209

35. Heiss WD, Habedank B, Klein JC et al (2004) Metabolic rates in small brain nuclei determined by high-resolution PET. J Nucl Med 45:1811-1815

36. Mason GF, Pan JW, Chu WJ et al (1999) Measurement of the tricarboxylic acid cycle rate in human grey and white matter in vivo by ${ }^{1} \mathrm{H}-\left[{ }^{13} \mathrm{C}\right]$ magnetic resonance spectroscopy at $4.1 \mathrm{~T}$. J Cereb Blood Flow Metab 19:1179-1188

37. de Graaf RA, Pan JW, Telang F et al (2001) Differentiation of glucose transport in human brain gray and white matter. J Cereb Blood Flow Metab 21:483-492

38. Eisenberg F Jr, Parthasarathy R (1987) Measurement of biosynthesis of myo-inositol from glucose 6-phosphate. Methods Enzymol 141:127-143

39. Ross B, Bluml S (2001) Magnetic resonance spectroscopy of the human brain. Anat Rec 265:54-84

40. Strange K, Emma F, Paredes A, Morrison R (1994) Osmoregulatory changes in myo-inositol content and $\mathrm{Na}^{+} /$myo-inositol cotransport in rat cortical astrocytes. Glia 12:35-43

41. Urenjak J, Williams SR, Gadian DG, Noble M (1992) Specific expression of $N$-acetylaspartate in neurons, oligodendrocyte-type2 astrocyte progenitors, and immature oligodendrocytes in vitro. $\mathrm{J}$ Neurochem 59:55-61

42. Simmons ML, Frondoza CG, Coyle JT (1991) Immunocytochemical localization of $N$-acetyl-aspartate with monoclonal antibodies. Neuroscience 45:37-45

43. Moffett JR, Ross B, Arun P, Madhavarao CN, Namboodiri AM (2007) $\mathrm{N}$-Acetylaspartate in the CNS: from neurodiagnostics to neurobiology. Prog Neurobiol 81:89-131

44. Wessels AM, Rombouts SA, Remijnse PL et al (2007) Cognitive performance in type 1 diabetes patients is associated with cerebral white matter volume. Diabetologia 50:1763-1769

45. Kodl CT, Franc DT, Rao JP et al (2008) Diffusion tensor imaging (DTI) identifies deficits in white matter microstructure in subjects with type 1 diabetes mellitus that correlate with reduced neurocognitive function. Diabetes 57:3083-3089 